University of Wollongong

Research Online

Australian Institute for Innovative Materials -

Papers

Australian Institute for Innovative Materials

$1-1-2013$

\title{
Platinum electrodeposition on unsupported single wall carbon nanotubes and its application as methane sensing material
}

\author{
Enid Contes-De Jesus \\ University Of Puerto Rico \\ Diana Santiago \\ University Of Puerto Rico \\ Gilberto Casillas \\ University of Texas at San Antonio, gilberto@uow.edu.au \\ Alvaro Mayoral \\ Universidad de Zaragoza \\ Cesar Magen \\ Universidad de Zaragoza
}

See next page for additional authors

Follow this and additional works at: https://ro.uow.edu.au/aiimpapers

Part of the Engineering Commons, and the Physical Sciences and Mathematics Commons

Research Online is the open access institutional repository for the University of Wollongong. For further information contact the UOW Library: research-pubs@uow.edu.au 


\title{
Platinum electrodeposition on unsupported single wall carbon nanotubes and its application as methane sensing material
}

\begin{abstract}
This paper reports the decoration of single wall carbon nanotubes (SWCNTs) with platinum (Pt) nanoparticles using an electrochemical technique, rotating disk slurry electrode (RoDSE). Pt/SWCNTs were electrochemically characterized by cyclic voltammetry technique (CV) and physically characterized through the use of transmission electron microscopy (TEM), energy dispersive spectroscopy - X-ray florescence (EDS-XRF) and X-ray diffraction (XRD). After characterization it was found that electrodeposited nanoparticles had an average particle size of $4.1 \pm 0.8 \mathrm{~nm}$. Pt/SWCNTs were used as sensing material for methane ( $\mathrm{CH} 4)$ detection and showed improved sensing properties in a range of concentration from $50 \mathrm{ppm}$ to $200 \mathrm{ppm}$ parts per million (ppm) at room temperature, when compared to other Pt/CNTs-based sensors. The use of this technique for the preparation of Pt/SWCNTs opens a new possibility in the bulk preparation of samples using an electrochemical method and thus their potential use in a wide variety of applications in chemical sensing, fuel cell and others.
\end{abstract}

\section{Keywords}

electrodeposition, unsupported, platinum, single, material, wall, carbon, nanotubes, its, application, methane, sensing

Disciplines

Engineering | Physical Sciences and Mathematics

\section{Publication Details}

Contes-De Jesus, E., Santiago, D., Casillas, G., Mayoral, A., Magen, C., Jose-Yacaman, M., Li, J. \& Cabrera, C. R. (2013). Platinum electrodeposition on unsupported single wall carbon nanotubes and its application as methane sensing material. Journal of The Electrochemical Society, 160 (2), H98-H104.

\section{Authors}

Enid Contes-De Jesus, Diana Santiago, Gilberto Casillas, Alvaro Mayoral, Cesar Magen, Miguel JoseYacaman, Jing Li, and Carlos R. Cabrera 


\title{
Platinum Electrodeposition on Unsupported Single Wall Carbon Nanotubes and Its Application as Methane Sensing Material
}

\author{
Enid Contes-de Jesus, ${ }^{\mathrm{a}}$ Diana Santiago, ${ }^{\text {a,* }}$ Gilberto Casillas, ${ }^{\mathrm{b}}$ Alvaro Mayoral, ${ }^{\mathrm{c}}$ \\ Cesar Magen, ${ }^{\mathrm{c}, \mathrm{e}}$ Miguel José-Yacaman, ${ }^{\mathrm{b}}$ Jing Li, ${ }^{\mathrm{d}, *}$ and Carlos R. Cabrera ${ }^{\mathrm{a}, *, \mathrm{z}}$
}

\author{
${ }^{a}$ NASA-URC Center for Advanced Nanoscale Materials, Department of Chemistry, University of Puerto Rico, Rio \\ Piedras Campus, San Juan 00936-8377, Puerto Rico \\ ${ }^{b}$ Department of Physics and Astronomy, University of Texas at San Antonio, One UTSA Circle, 78249 San Antonio, \\ Texas, USA \\ ${ }^{c}$ Laboratorio de Microscopias Avanzadas, Instituto de Nanociencia de Aragon, Universidad de Zaragoza, 50018 \\ Zaragoza, Spain \\ ${ }^{d}$ Center for Nanotechnology, NASA Ames Research Center, Moffett Field, California 94035, USA \\ ${ }^{e}$ Departamento de Fisica de la Materia Condensada, Universidad de Zaragoza, 50009 Zaragoza, Spain
}

\begin{abstract}
This paper reports the decoration of single wall carbon nanotubes (SWCNTs) with platinum (Pt) nanoparticles using an electrochemical technique, rotating disk slurry electrode (RoDSE). Pt/SWCNTs were electrochemically characterized by cyclic voltammetry technique (CV) and physically characterized through the use of transmission electron microscopy (TEM), energy dispersive spectroscopy - X-ray florescence (EDS-XRF) and X-ray diffraction (XRD). After characterization it was found that electrodeposited nanoparticles had an average particle size of $4.1 \pm 0.8 \mathrm{~nm}$. Pt/SWCNTs were used as sensing material for methane $\left(\mathrm{CH}_{4}\right)$ detection and showed improved sensing properties in a range of concentration from $50 \mathrm{ppm}$ to $200 \mathrm{ppm}$ parts per million (ppm) at room temperature, when compared to other Pt/CNTs-based sensors. The use of this technique for the preparation of Pt/SWCNTs opens a new possibility in the bulk preparation of samples using an electrochemical method and thus their potential use in a wide variety of applications in chemical sensing, fuel cell and others.
\end{abstract}

(C) 2012 The Electrochemical Society. [DOI: 10.1149/2.054302jes] All rights reserved.

Manuscript submitted July 30, 2012; revised manuscript received November 19, 2012. Published December 1, 2012.

Carbon nanotubes (CNT) have been the focus of numerous studies since their discovery in $1991 .{ }^{1}$ CNTs have been proposed as ideal materials for different potential applications ${ }^{2-4}$ including energy storage, ${ }^{5}$ nanoelectronics, ${ }^{6}$ chemical sensors, ${ }^{7,8}$ and biosensors, ${ }^{9}$ among others. Single wall carbon nanotubes (SWCNTs) possess characteristics ${ }^{3}$ such as high surface area, high thermal and mechanical stability, and functionalization capability, which make them suitable as matrix for supporting nanoparticles (NPs).

$\mathrm{Pt} / \mathrm{SWCNTs}$ composites are prepared by various synthetic methods ${ }^{10-12}$ including impregnation, precipitation, colloidal, sputtering, and others, which offer large-scale production. Electrodeposition technique has shown advantages over the aforementioned methods due to the fact that particle size, distribution and loading of metal particles can be controlled by the variation of time, applied potential and concentration. However, conventional electrochemical deposition of $\mathrm{Pt}$ NPs on SWCNTs has been possible when SWCNTs were grown, cast or chemically attached to a substrate or were used in the form of thin film or foil ${ }^{7,13}$ which limits the production quantity of Pt/SWCNTs composite for its use in real applications.

Cabrera's research group recently reported the use of the rotating disk-slurry electrode (RoDSE) technique for the large-scale production of well-dispersed Pt NPs on unsupported carbon black. ${ }^{14}$ In this paper we report the use of the RoDSE technique for the bulk preparation of Pt/SWCNTs. The purpose of the current work is to demonstrate that it is possible to electrodeposit Pt NPs onto unsupported SWCNTs. In addition, to show a potential application, where we used the prepared Pt/SWCNTs as sensing material for the ppm level detection of $\mathrm{CH}_{4}$ at room temperature.

\section{Experimental}

SWCNTs purification and oxidation.- SWCNTs (Carbon Nanotechnologies) were purified to remove iron catalyst. Briefly, the as received SWCNTs were refluxed in nitric acid $\left(\mathrm{HNO}_{3}\right) 2.6 \mathrm{M}$ at $200^{\circ} \mathrm{C}$ for 24 hours. Dilution, decantation and centrifugation were performed in order to increase the $\mathrm{pH}$ above 3 , followed by filtration using a Millipore system and vacuum pump and rinsed thoroughly with nanopure water (Barnsted). The purified SWCNTs were oven dried at $150^{\circ} \mathrm{C}$ for 3 hours. In order to obtain o-SWCNTs, the purified SWCNTs

\footnotetext{
*Electrochemical Society Active Member.
}

${ }^{\mathrm{z}}$ E-mail: carlos.cabrera2@upr.edu were suspended in a 3:1 mixture of $\mathrm{H}_{2} \mathrm{SO}_{4}$ (Optima) and $\mathrm{HNO}_{3}$ and sonicated for 8 hours at $35-40^{\circ} \mathrm{C}$. Dilution, decantation and centrifugation were repeated followed by filtration and rinsing. The sample was allowed to dry at room temperature.

Pt electrodeposition on SWCNTs (Pt/SWCNTs). - A slight variation of the RoDSE procedure reported by our group ${ }^{14,15}$ was performed. In brief, $30 \mathrm{mg}$ of o-SWCNTs were mixed with $\mathrm{H}_{2} \mathrm{SO}_{4} 0.1 \mathrm{M}$ and $2 \mathrm{~mL}$ of $\mathrm{K}_{2} \mathrm{PtCl}_{6} 5 \mathrm{mM}$ dissolved in $\mathrm{H}_{2} \mathrm{SO}_{4}$ $0.1 \mathrm{M}$, sonicated for 1 hour to form the slurry. The slurry was then transferred to the center tube of a 3-electrode cell ( 3 compartments separated by fritted glass, one for each electrode). An illustration of the 3-electrode cell can be found in reference. ${ }^{15}$ A glassy carbon RDE, $\mathrm{Ag} / \mathrm{AgCl}$ (0.197 V vs. NHS) and a graphite rod were used as working, reference and counter electrodes, respectively. The electrodeposition process was done by placing the working electrode in the slurry and with an angular velocity of $900 \mathrm{rpm}$. Under a nitrogen atmosphere, a constant voltage of $-0.2 \mathrm{~V}$ vs $\mathrm{Ag} / \mathrm{AgCl}$ was applied for 2 hours. This process was repeated 4 consecutive times and the changes of current as function of time (chronoamperometry) were recorded. When the electrodeposition was completed, the slurry was removed from the cell, filtrated and rinsed thoroughly with nanopure water in order to remove residues of non-reduced species, or free standing Pt NPs, if any.

Ink paste preparation and electrode modification.- Glassy carbon electrodes (GCE) (diameter: $3 \mathrm{~mm}$ Bioanalytical System) were mechanically polished with alumina $(1.0,0.3$ and $0.05 \mu \mathrm{m})$ and rinsed thoroughly with nanopure water. The electrodes were then sonicated in ethanol and nanopure water in order to remove any alumina residues and air-dried at room temperature. An ink paste was prepared by mixing $0.5 \mathrm{mg}$ of the sample (o-SWCNTs or Pt/SWCNTs) with $700 \mu \mathrm{L}$ of dimethylformamide (DMF) and $50 \mu \mathrm{L}$ of Nafion $5 \mathrm{wt} \%$ and sonication for $1 \mathrm{hr}$. An $8 \mu \mathrm{L}$ droplet of the ink paste was cast over the surface of the GCE. The modified electrode was then allowed to air-dry overnight and ready for electrochemical characterization.

Electrochemical characterization.-All electrochemical measurements were done in $0.50 \mathrm{M} \mathrm{H}_{2} \mathrm{SO}_{4}$. A three-electrode cell using the modified $\mathrm{GCE}$ as working electrode, $\mathrm{Ag} / \mathrm{AgCl}$ as reference electrode, a Pt wire as counter electrode and with a Basic Electrochemical System (EG\&G). All the potentials are reported vs. $\mathrm{Ag} / \mathrm{AgCl}$. 
CV.- $\mathrm{CV}$ for o-SWCNTs samples was done at potentials from -0.2 to $0.9 \mathrm{~V}$ vs. $\mathrm{Ag} / \mathrm{AgCl}$ and at a scan rate of $100 \mathrm{mV} \mathrm{sec}{ }^{-1}$. Pt/SWCNTs samples were cycled between -0.22 and $1.2 \mathrm{~V}$ vs. $\mathrm{Ag} / \mathrm{AgCl}$, at a scan rate of $1 \mathrm{mV} \mathrm{sec}^{-1}$.

CO stripping.-For the $\mathrm{CO}$ stripping experiment, $\mathrm{CO}$ was bubbled into the 3-electrode cell for 15 minutes at an applied potential of $0.100 \mathrm{~V}$ vs. $\mathrm{Ag} / \mathrm{AgCl}$. Then, Ar was bubbled for another 15 minutes to displace the $\mathrm{CO}$ from solution. Afterwards, two consecutive scan cycles were performed at potentials between -0.2 and $0.9 \mathrm{~V}$ vs. $\mathrm{Ag} / \mathrm{AgCl}$, at a scan rate of $20 \mathrm{mV} \mathrm{sec}{ }^{-1}$.

Surface characterization.- To study and track the changes in composition and morphology, different techniques for surface analysis were used. X-ray photoelectron spectroscopy (XPS) data was acquired using a PHI 5600 ci spectrometer with monochromatic Al-K $\alpha$ source. To obtain the survey analysis, the spectra were recorded at a take off angle and pass energy of $45^{\circ}$ and $187.85 \mathrm{eV}$, respectively. Energy dispersive spectroscopy-X-ray fluorescence (EDS-XRF) (JEOL JSM$5800 \mathrm{LV}$ ) was used for elemental analysis. X-ray diffraction (XRD) analysis was done using a Rigaku Ultima II diffractometer and $\mathrm{K} \alpha$ incident X-ray source. Scans were recorded between 20 and $90^{\circ}$ in the $2 \theta$ range, step size of $0.02^{\circ}$ and a speed of $1.00 \mathrm{deg}^{\mathrm{min}}{ }^{-1}$.

Transmission electron microscopy (TEM) images were obtained using a TITAN 60-300 cubed, operated at $80 \mathrm{kV}$. The spherical aberrations were corrected trough a CESCOR corrector for the objective lens, reaching a 0.8 -angstrom point resolution. The cube maintained the equipment isolated from any external vibration. The images were recorded for 0.4 seconds each. Nanostructures were characterized in a JEOL JEM-ARM200F electron microscope operated in STEM mode.

Sensor preparation and gas sensing experiments.- Figure 1 shows the printed circuit board (PCB) chip containing 16 interdigitated electrodes (IDEs) used for the gas sensing experiments with a similar platform as those previously reported by Y. Lu, et al ${ }^{16,17}$ Each IDE has fingers with a width of $80 \mu \mathrm{m}$ and gap distance between fingers of $115 \mu \mathrm{m}$. The o-SWCNTs and Pt/SWCNTs nanomaterials were suspended in DMF $(0.018 \% \mathrm{w} / \mathrm{w})$ and sonicated. The samples were then deposited over sensors using a micropipette. After sample deposition, the sensors were baked $\left(80^{\circ} \mathrm{C}\right.$ and vacuum) to remove possible solvent traces adhered to the sample. An initial resistance of several hundreds $\mathrm{k} \Omega$ was obtained from made sensors. Each test was repeated at least three times for reproducibility purposes. The

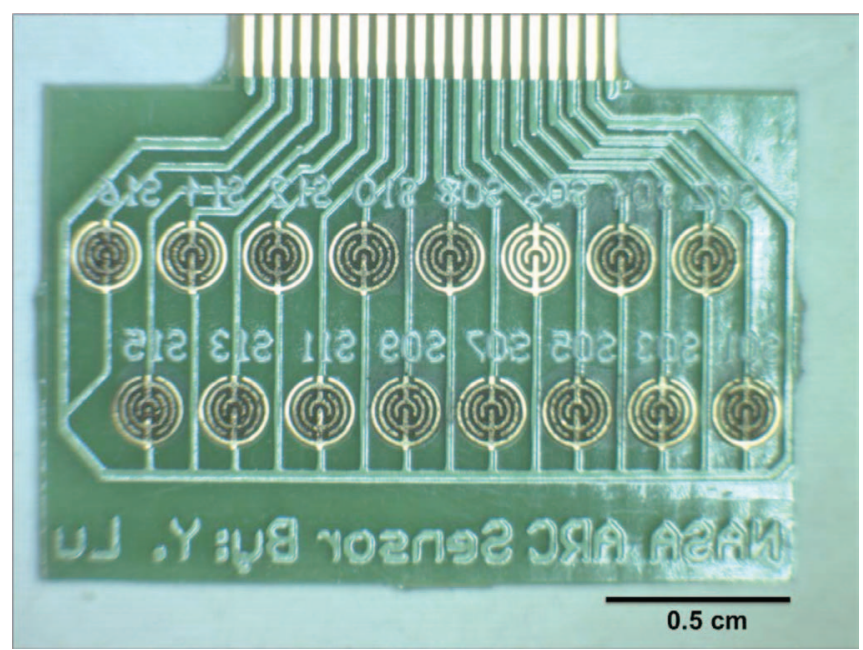

Figure 1. Picture of printed circuit board (PCB) chip (IDE) containing 16 interdigitated electrodes (IDEs) used for the gas sensing experiments with a similar platform as those previously reported by Y. Lu, et al. ${ }^{16,17}$ Each IDE has fingers with a width of $80 \mu \mathrm{m}$ and gap distance between fingers of $115 \mu \mathrm{m}$. sensors were exposed to $\mathrm{CH}_{4}$ at concentrations of $50,100,125$ and 200 ppm provided by an Environics 2040, a gas blending and dilution system using air as purge and diluting gas at constant flow rate of $400 \mathrm{~cm}^{3} / \mathrm{min}$. Sensing experiments were carried out as follows: sensors were initially exposed to air for 35 minutes to establish a baseline and then exposed to $\mathrm{CH}_{4}$ for 3 minutes at each concentration and 5 minute purge in between concentrations. All gas-sensing experiments were carried out at room temperature and with $40 \%$ relative humidity (RH). Changes in resistance as function of time were recorded using a customized LabVIEW program. Relative responses for each concentration were calculated using the following equation: $R_{\text {rel }}=\frac{\left(R_{i}-R_{0}\right)}{R_{0}}$, where $R_{0}$ is the initial resistance before each $\mathrm{CH}_{4}$ exposure and $\mathrm{R}_{\mathrm{i}}$ is the resistance of the sensor during the $\mathrm{CH}_{4}$ exposure. The noise $(\mathrm{N})$ of the sensors was determined by calculating the root mean square (rms) of the baseline. Responses with a signal to $\mathrm{N}$ ratio $(\mathrm{s} / \mathrm{N})$ greater or equal to 3 were considered. Calibration curves were obtained by making a graph of $\left(\mathrm{R}_{\mathrm{i}}-\mathrm{R}_{0}\right)$ as function of concentration. The slope of the calibration curve is the sensitivity. Finally, the detection limit (DL) of each sensor was calculated with the following equation: 3(rms/slope)

\section{Results and Discussion}

Purification-oxidation process. - The purification process of SWCNTs was carried out to eliminate the iron particles that are used as catalyst (Fe-catalyst) in their production and is important because these particles might interfere in some applications as well as in electrochemical studies. Figure 2 shows the XPS survey analysis spectra for as-received SWCNTs and oxidized SWCNTs (o-SWCNTs). It can be observed the elimination of the peaks corresponding to Fe2p, after the processes of purification and oxidation. It is also noticeable an increase in the intensity of the O1s signal for o-SWCNTs relative to that of as-received SWCNTs, as a result of the oxidation process.

Relative elemental composition of the samples is shown in Table I and it suggests the removal of the Fe-catalyst. However, it is well known that traces of Fe will always be present. An increase in the

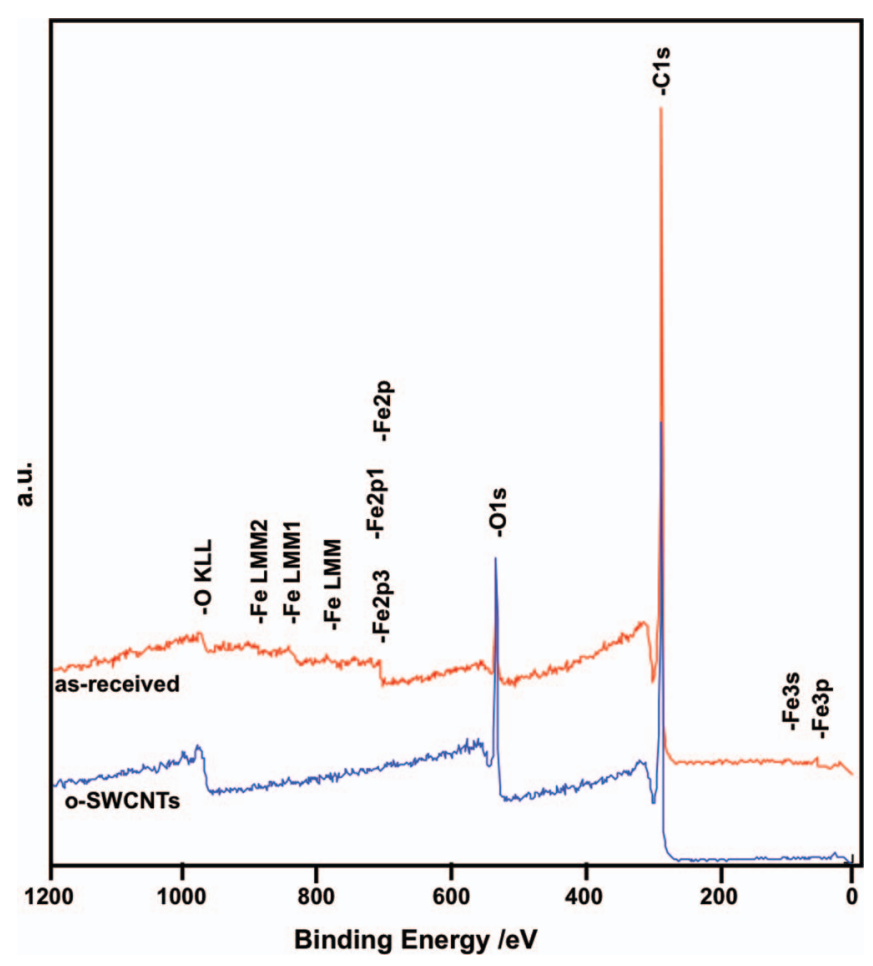

Figure 2. X-ray photoelectron spectroscopy survey spectra for as-received SWCNTs and o-SWCNTs. 
Table I. Relative atomic composition for as received and oxidized SWCNTs obtained by X-ray photoelectron spectroscopy. The elemental composition data was used to determine the oxygen-carbon atomic ratio.

\begin{tabular}{lcccc} 
SWCNTs sample & C 1s\% & O1s\% & Fe2p $\%$ & O/C \\
\hline as received SWCNTs & 91.39 & 6.94 & 1.25 & 0.08 \\
o-SWCNTs & 79.04 & 20.96 & 0.00 & 0.27
\end{tabular}

relative amount of $\mathrm{O} 1 \mathrm{~s}$ after the purification and oxidation processes can also be noticed. Values from Table I were also used to calculate the oxygen to carbon atomic ratio $(\mathrm{O} / \mathrm{C})$. Before purification, the $\mathrm{O} / \mathrm{C}$ value was 0.08 . After the purification process, the $\mathrm{O} / \mathrm{C}$ was 0.27 , which is 3.4 times larger than the as-received SWCNTs. In fact, the $\mathrm{O} / \mathrm{C}$ value of 0.27 is comparable with the $\mathrm{O} / \mathrm{C}$ of 0.25 reported by Cabrera's research group after treating SWCNTs with a similar purificationoxidation process. ${ }^{18}$ Cyclic voltammetry $(\mathrm{CV})$ was also performed to as received and o-SWCNTs samples. When comparing the two voltammograms shown in Figure 3, it can be observed that for oSWCNTs sample, there is an increase in the capacitance double layer due to an increase in the oxygen surface concentration that resulted from the acid treatment. ${ }^{19,20}$ In the same way, two broad peaks around $0.4 \mathrm{~V}$ vs. $\mathrm{Ag} / \mathrm{AgCl}$ can be observed and they are attributed to oxygencontaining functional groups like carboxylic acids and quinines. ${ }^{19,21}$

Figure 4 shows a TEM micrograph of a clean single wall carbon nanotubes with a diameter of $1 \mathrm{~nm}$. It is also important to note that the oxidation processes was aggressive enough to create functionalities but without losing the SWCNTs structure.

Electrodeposition process. - In order to do the electrodeposition process it is very important to have the o-SWCNTs suspended in aqueous slurry. Considering their highly hydrophobic nature, the oxygen-containing groups in the SWCNTs created during the purification/oxidation process help to improve their wettability, and thus on the formation of the slurry. Once the slurry is placed on the cell and in contact with the glassy carbon rotating disk electrode RDE (working electrode), the electrodeposition process is carried out. During the electrodeposition process the rotation of the RDE creates a hydrodynamic flow that keeps the slurry in movement and suspended in the cell. Pt NPs are electrodeposited over the SWCNTs as they reach the surface of the RDE while a potential of $-0.2 \mathrm{~V}$ is constantly applied. The amount of Pt electrodeposited on SWCNTs (Pt loading) was determined using an Inductively Coupled Plasma- Mass Spectrophotometer (ICP-MS). The average loading of the samples was $1.22 \pm 0.13 \%$ w/w. Comparable results were obtained with XPS and EDS-XRF analysis.

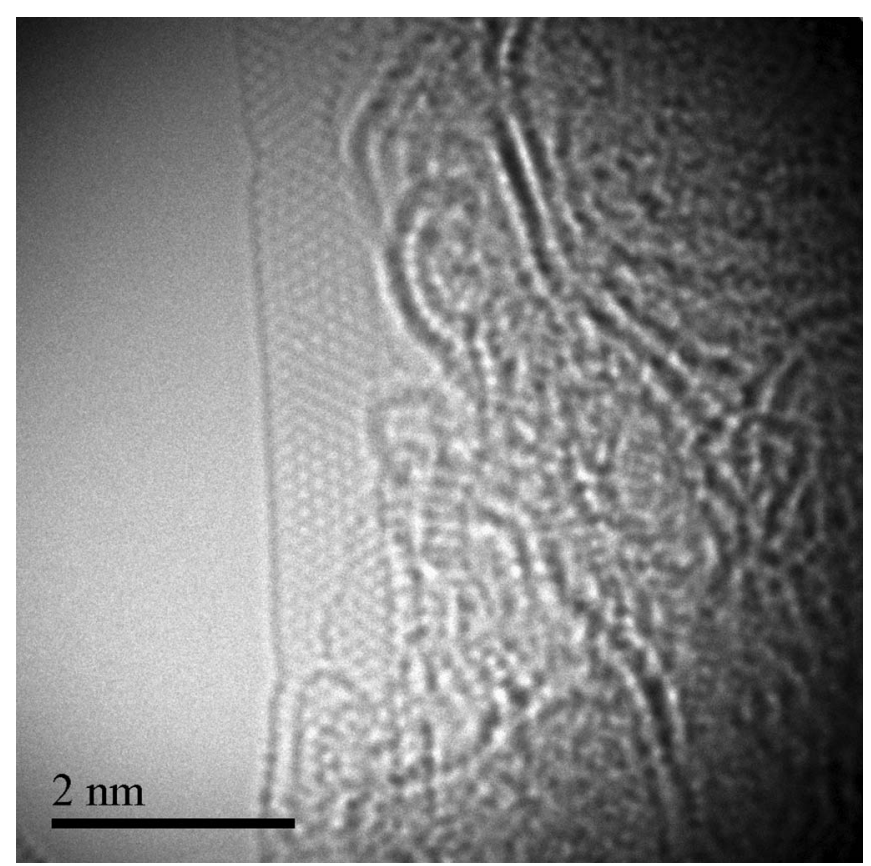

Figure 4. Transmission electron microscopy micrograph of o-SWCNTs.

Two potential situations were identified while using RoDSE technique. The first one is that the working electrode is material is glassy carbon, which is also carbonaceous material and it is expected that Pt may deposit on its surface instead of SWCNTs. The second one is related to the reduction reaction from $\mathrm{PtCl}_{6}{ }^{-2}$ to $\mathrm{Pt}^{0}$ :

$$
\begin{gathered}
\mathrm{PtCl}_{6}^{-2}+2 \mathrm{e}^{-} \rightarrow \mathrm{PtCl}_{4}^{+2}+2 \mathrm{Cl}^{-} \\
\mathrm{PtCl}_{4}^{+2}+2 \mathrm{e}^{-} \rightarrow \mathrm{Pt}^{0}+4 \mathrm{Cl}^{-}
\end{gathered}
$$

Considering the reduction reaction presented above, there is possibility of having intermediates (partially reduced $\mathrm{Pt}^{+2}$ species) trapped within the SWCNTs due to defects in their structure created during the purification-oxidation process and/or between entangled SWCNTs. However, these are not considered to be major problems since the objective of electrodepositing Pt NPs on SWCNTs was met, as demonstrated with electrochemical and surface characterization that are discussed in the following sections.

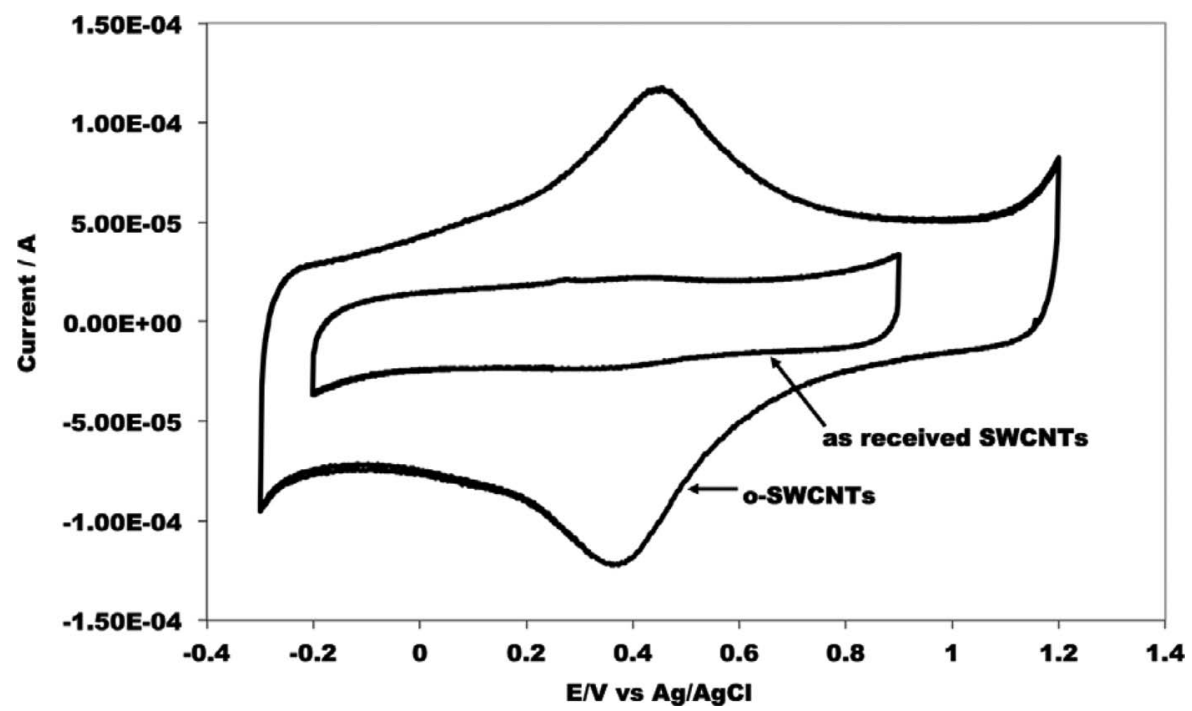

Figure 3. Cyclic voltammetries in $0.50 \mathrm{M} \mathrm{H}_{2} \mathrm{SO}_{4}$ at $100 \mathrm{mV} \mathrm{sec}^{-1}$ for as-received and o-SWCNTs. 


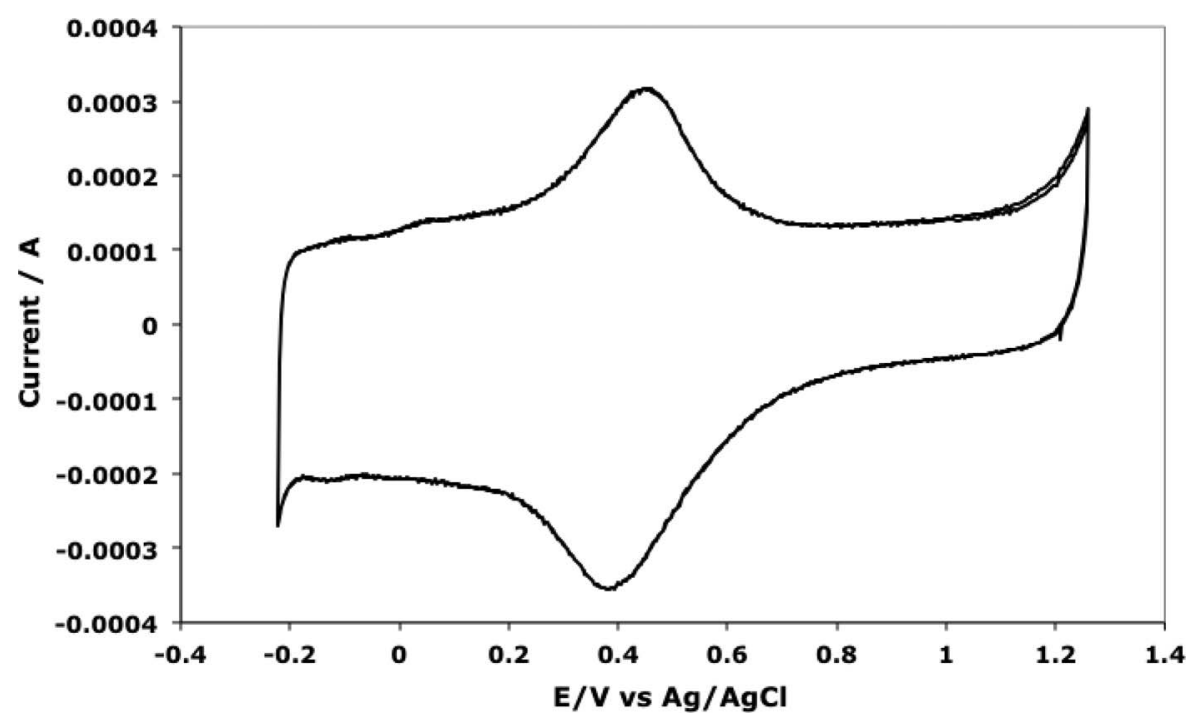

Figure 5. Cyclic voltammetry of $\mathrm{Pt} / \mathrm{SWCNTs}$ in $0.50 \mathrm{M} \mathrm{H}_{2} \mathrm{SO}_{4}$ at $100 \mathrm{mV} \mathrm{sec}^{-1}$.
Electrochemical characterization. - To perform electrochemical characterization, the Pt/SWCNTs samples, prepared by the RoDSE technique, were prepared into an ink-paste and cast over a glassy carbon electrode (GCE). Figure 5 shows the $\mathrm{CV}$ of Pt/SWCNTs done in $0.50 \mathrm{M} \mathrm{H}_{2} \mathrm{SO}_{4}$ at $100 \mathrm{mv} / \mathrm{sec}$. The $\mathrm{CV}$ shows small peaks corresponding to hydrogen adsorption and desorption on Pt NPs. It also shows the peaks at around $0.4 \mathrm{~V}$ corresponding to oxygen-containing functional groups of the o-SWCNTs. Since carbon monoxide $(\mathrm{CO})$ is adsorbed on $\mathrm{Pt}$ active sites (poisoning), $\mathrm{CO}$ stripping was performed to determine electrochemically active surface area (EAS) (Fig. 6). After the exposure of the sample to $\mathrm{CO}$, the $\mathrm{CO}$ stripping peak potential appeared at around $0.6 \mathrm{~V}$ vs. $\mathrm{Ag} / \mathrm{AgCl}$. To calculate the $\mathrm{CO}$ stripping charge, the area under the peak was integrated and the charge corresponding to the double layer was subtracted. The obtained charge was $3.708 \times 10^{-5} \mathrm{C}$. This value was used to calculate the $\mathrm{CO}$ surface area in $\mathrm{cm}^{2}$ was calculated using the following equation: ${ }^{22}$

$$
S_{C O}=\frac{Q_{C O}}{0.420 m C \mathrm{~cm}^{-2}}
$$

where $\mathrm{Q}_{\mathrm{CO}}$ is the $\mathrm{CO}$ stripping charge $(\mathrm{mC})$ and $0.420 \mathrm{mC} \mathrm{cm}^{-2}$ is the monolayer of the CO adsorbed. The obtained EAS was $139 \mathrm{~m}^{2} / \mathrm{g}$ of Pt.

Surface characterization and elemental analysis.- EDS-XRF was used to obtain elemental analysis of the sample and the spectrum is shown in Figure 7. The presence of $\mathrm{Pt}$ was detected as well as the presence of chlorine $(\mathrm{Cl})$, potassium $(\mathrm{K})$ and $\mathrm{Fe}$, which correspond to ligands and counter ions of the $\mathrm{Pt}$ salt precursor used during the electrodeposition process and remaining traces of catalyst (SWCNTs formation), respectively.

TEM and scanning electron transmission microscopy (STEM) images were recorded in order to observe the Pt NPs electrodeposited over the SWCNTs. Figure 8 shows bright field (BF) TEM micrographs of the Pt/SWCNTs sample. Well-dispersed, small dark particles that correspond to NPs and small clusters of Pt over the SWCNTs bundles are shown in Figure 8a. Pt NPs with diameters smaller than $10 \mathrm{~nm}$ can be observed in Figure 8b. Figure 9a shows the graph of particle size distribution obtained from the TEM image shown in Figure $9 \mathrm{~b}$.

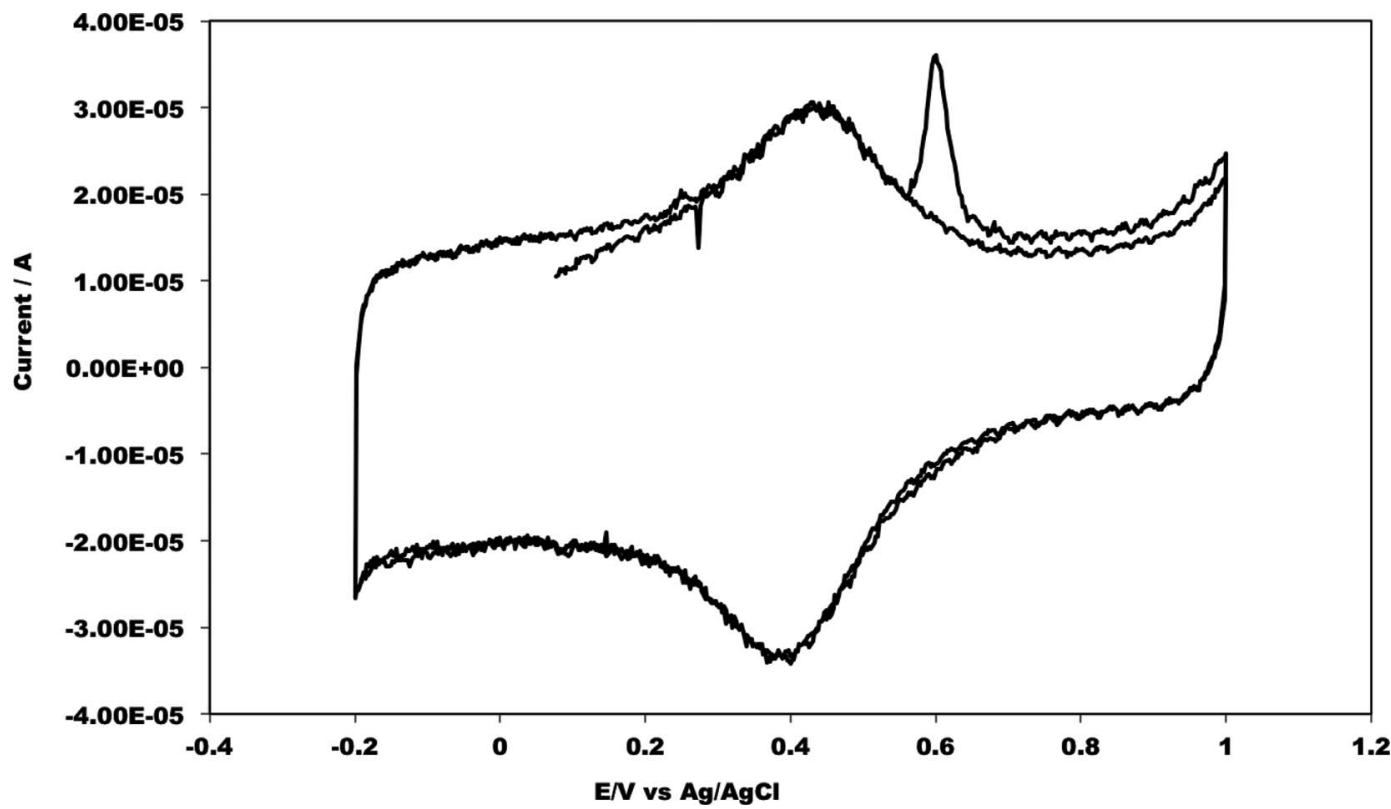

Figure 6. Electrochemical CO stripping. First two cycles after $\mathrm{CO}$ exposure done in $\mathrm{H}_{2} \mathrm{SO}_{4} 0.5 \mathrm{M}$ at $20 \mathrm{mV} \mathrm{sec}{ }^{-1}$. 


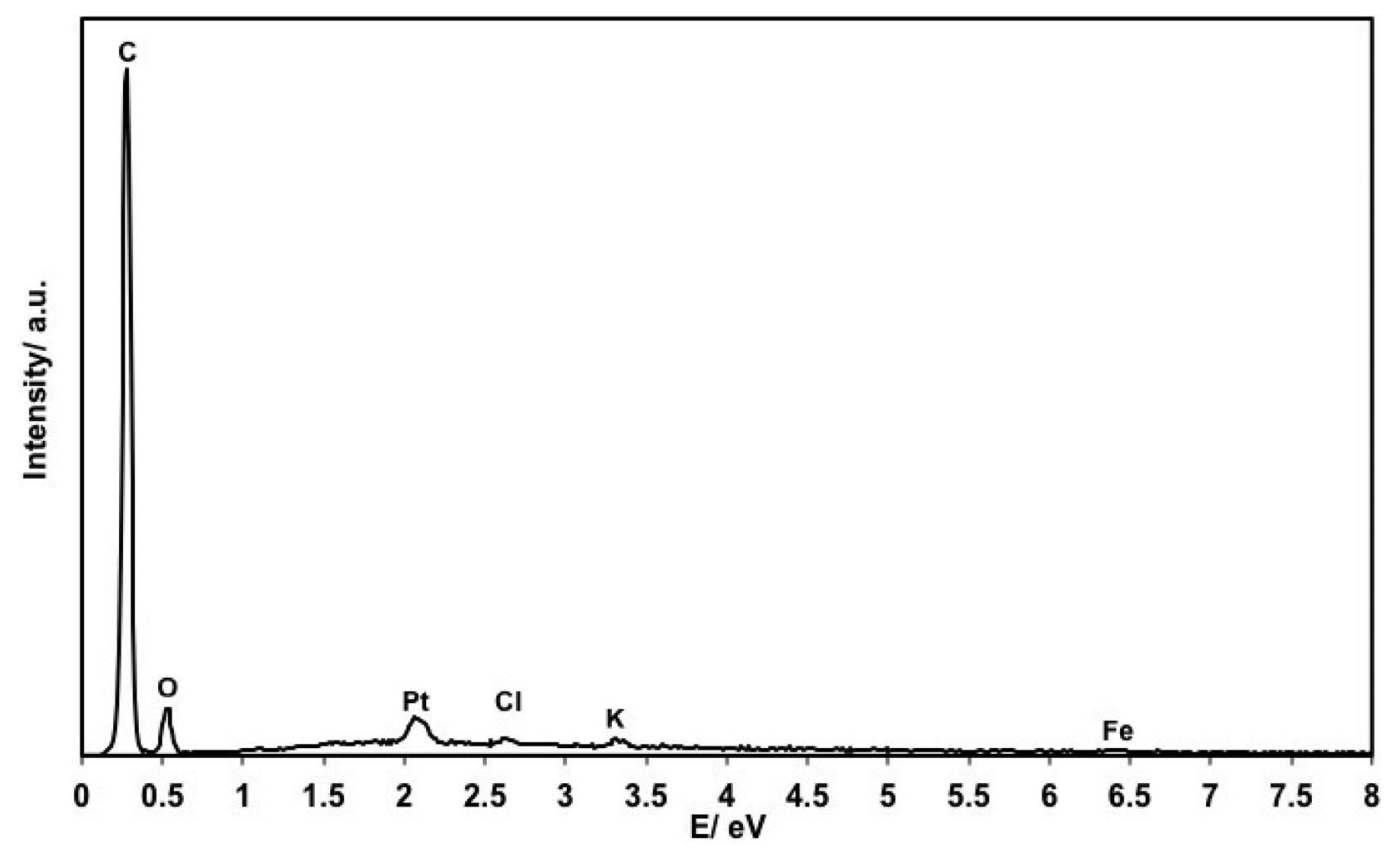

Figure 7. Energy dispersive spectroscopy- X-ray fluorescence spectra for Pt/SWCNTs.

The average size of particles is $4.1 \pm 0.8 \mathrm{~nm}$ and this value is similar to the $5 \pm 2 \mathrm{~nm}$ size for Pt NPs prepared by the RoDSE technique. ${ }^{14}$

XRD data was used to analyze the Pt NPs crystalline structures (see Figure 10). The o-SWCNTs sample showed peaks around $2 \theta=25^{\circ}$ and $42^{\circ}$ assigned to $C(002)$ and $C(100)$, respectively, and correspond to the graphitic structure of the SWCNTs. The Pt containing sample showed the characteristics peaks of Pt with a face cubic centered (FCC) structure. The diffraction peaks at $2 \theta$ of ca. $39.5^{\circ}, 46.5^{\circ}, 67.5^{\circ}, 81.5^{\circ}$ and $86^{\circ}$ correspond to $\mathrm{Pt}$ (111), (200), (311) and (222), respectively. ${ }^{23}$ It also shows the peak corresponding to $C(002)$, which means that the SWCNTs conserved its crystalline graphitic structure, even after the purification and oxidation processes that are well known to damage their structure. Using the peak Pt (111) and Scherrer's equation $\left(d=0.89 \lambda_{K \alpha 1} / B_{2 \theta} \cos \theta_{\max }\right)$ the average crystallite size is estimated to be $5.4 \mathrm{~nm}$, which is comparable to the value obtained for Pt particle size from TEM.

$\mathrm{CH}_{4}$ detection. - Theoretical and experimental studies have demonstrated that sensors based on pristine CNTs have poor sensitivity detecting non-polar gases mainly due to its chemical stability from their strong $s p^{2}$ bonds and weak $s p^{3}$ bonds at the tube ends which give the inability of the $\mathrm{CH}_{4}$ molecules to accept or donate electrons and subsequently cannot produce the changes in the conductance of CNTs. ${ }^{24,25}$ Taking advantage of their modification capability, CNTs modified with functional groups, dopants, metallic NPs, metal-oxide NPs and polymers have shown to overcome this limitation. Several reviews focused on modified CNTs for gas sensor applications have been recently published. ${ }^{8,26-29}$

All $\mathrm{CH}_{4}$ sensing experiments were carried out with $40 \% \mathrm{RH}$ present, at room temperature with a constant flow of $400 \mathrm{~cm}^{3} / \mathrm{min}$. As observed in Figure 11a, o-SWNTs samples did not show any changes in resistance for any of the tested concentrations. A typical sensor response of Pt/SWNTs for $\mathrm{CH}_{4}$ detection showing an increase in resistance can be observed as $\mathrm{CH}_{4}$ was introduced (Figure 11b). Sensor's response is a relative change of its resistance defined as:

$$
R_{r e l}=\frac{\left(R_{i}-R_{0}\right)}{R_{0}}
$$

where $\mathrm{R}_{0}$ is the initial resistance before $\mathrm{CH}_{4}$ exposure and $\mathrm{R}_{\mathrm{i}}$ is the resistance of the sensor during the $\mathrm{CH}_{4}$ exposure. Calibration curve (Figure 11c) from the sensor responses shows that a linear fit best describes the relation of the sensor's responses as function of $\mathrm{CH}_{4}$ concentration.

The results obtained in this work are in good agreement with previous theoretical and experimental results for other CNT-based sensors used for $\mathrm{CH}_{4}$ detection. ${ }^{24,30,31}$ As suggested by L. Valentini et al. the increase in resistance can be attributed to $\mathrm{CH}_{4}$ acting as an electron donor and thus reducing the hole density in the P-type Pt/SWNTs composite. ${ }^{32} \mathrm{Pt} / \mathrm{SWCNTs}$ sensors were able to detect the lower tested concentration $(50 \mathrm{ppm})$ and showed to have good reversible at room temperature. Here, we demonstrate an improvement in sensitivity and operation temperature of the Pt/SWCNTs sensors, when compared to the work recently published in which Pt/MWCNTs sensors were for the detection of $\mathrm{CH}_{4}(98-5600 \mathrm{ppm})$ at $120^{\circ} \mathrm{C}^{33}$

\section{Conclusions}

Unsupported SWCNTs were successfully modified with Pt NPs using the RoDSE technique. To best of our knowledge, this is the first time that an electrodeposition method is used for the bulk production of Pt/SWCNTs. The as-received SWCNTs were purified and oxidized before Pt electrodeposition. XPS and CV confirmed removal of the Fe-catalyst and increase in concentration of oxygen-containing groups in SWCNTs. During the electrodeposition process, a slurry solution containing suspended o-SWCNTs was used and a constant applied potential was done via the RDE. With this technique, $\mathrm{Pt}$ was electrodeposited on SWCNT with an average loading of $1.22 \% \mathrm{w} / \mathrm{w}$. The EDS-XRF elemental analysis confirmed the presence of $\mathrm{Pt}$ as well as $\mathrm{Cl}$ and $\mathrm{K}$, which are components of the Pt precursor salt and XRD data showed that the electrodeposited $\mathrm{Pt}^{0}$ has FCC structure. TEM images showed the presence of electrodeposited Pt atoms, atom clusters, and NPs with an average size of $4.1 \pm 0.8 \mathrm{~nm}$.

The possibility of using the Pt/SWCNTs for gas sensing application was demonstrated. This electrochemically Pt modified unsupported SWCNT proved to be an excellent sensing material for ppm level detection of $\mathrm{CH}_{4}$ at room temperature. From the calibration curve, the sensor's responses were proportional to $\mathrm{CH}_{4}$ concentrations.

We consider that this work opens a new and alternative way to prepare metallic NPs supported on SWCNTs in large-scale. Furthermore, optimization of various parameters like the metal precursor concentration, deposition time and angular velocity of the rotating working 

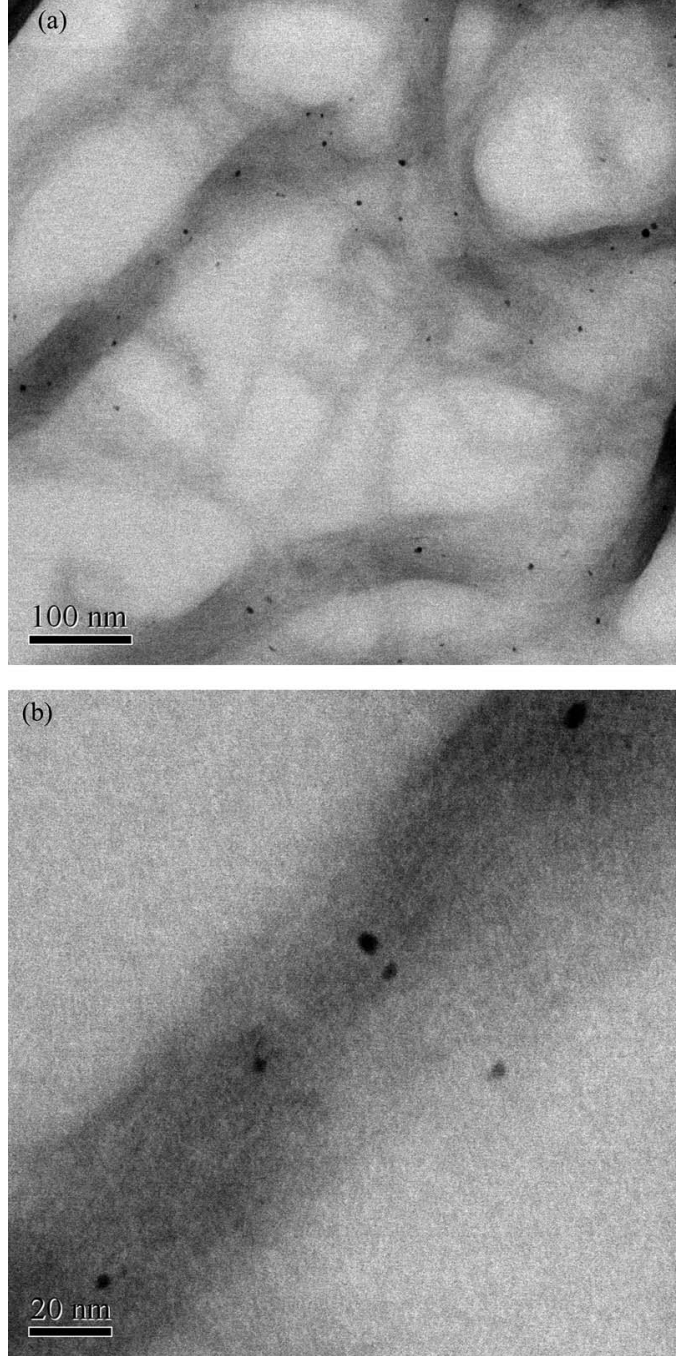

Figure 8. Bright Field-Transmission electron microscopy images of Pt/SWCNTs.
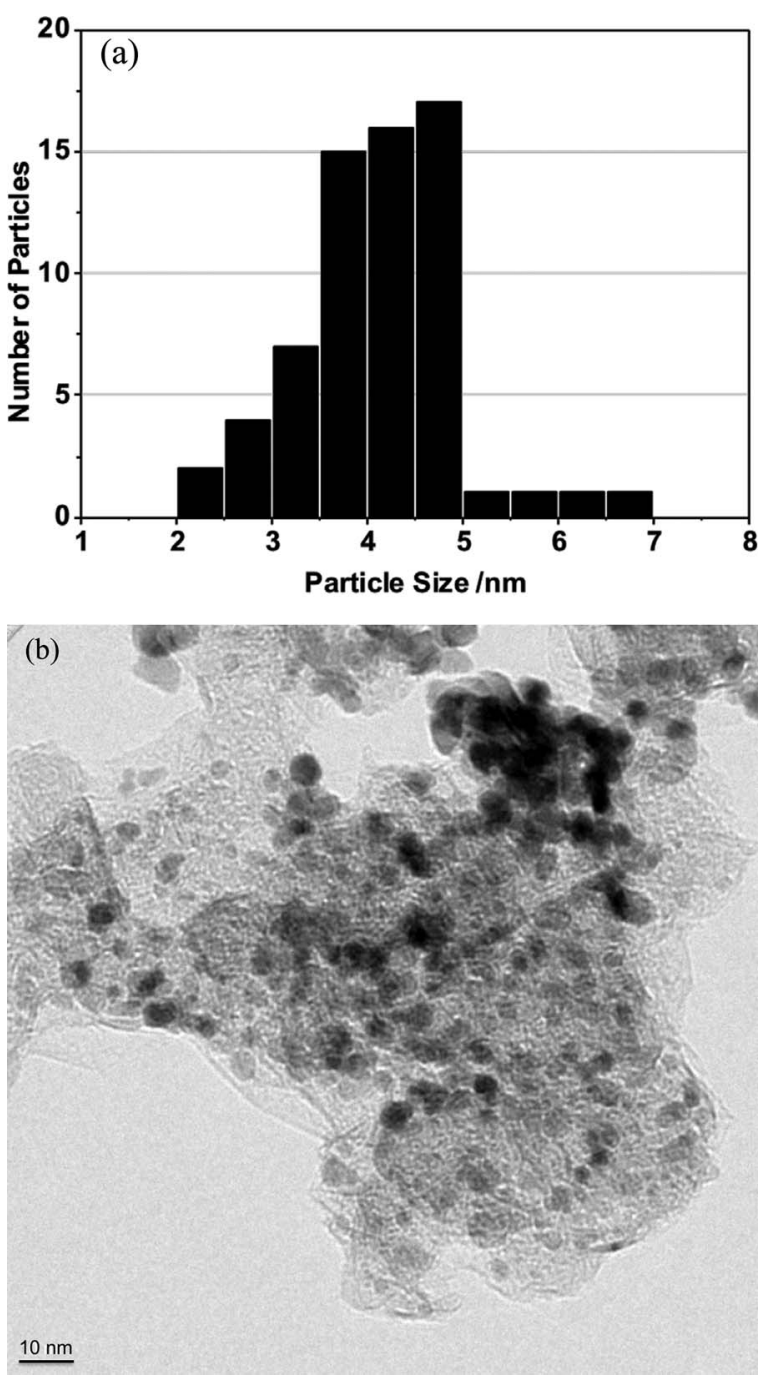

Figure 9. Graph of particle size distribution (a) from transmission electron microscopy image (b)

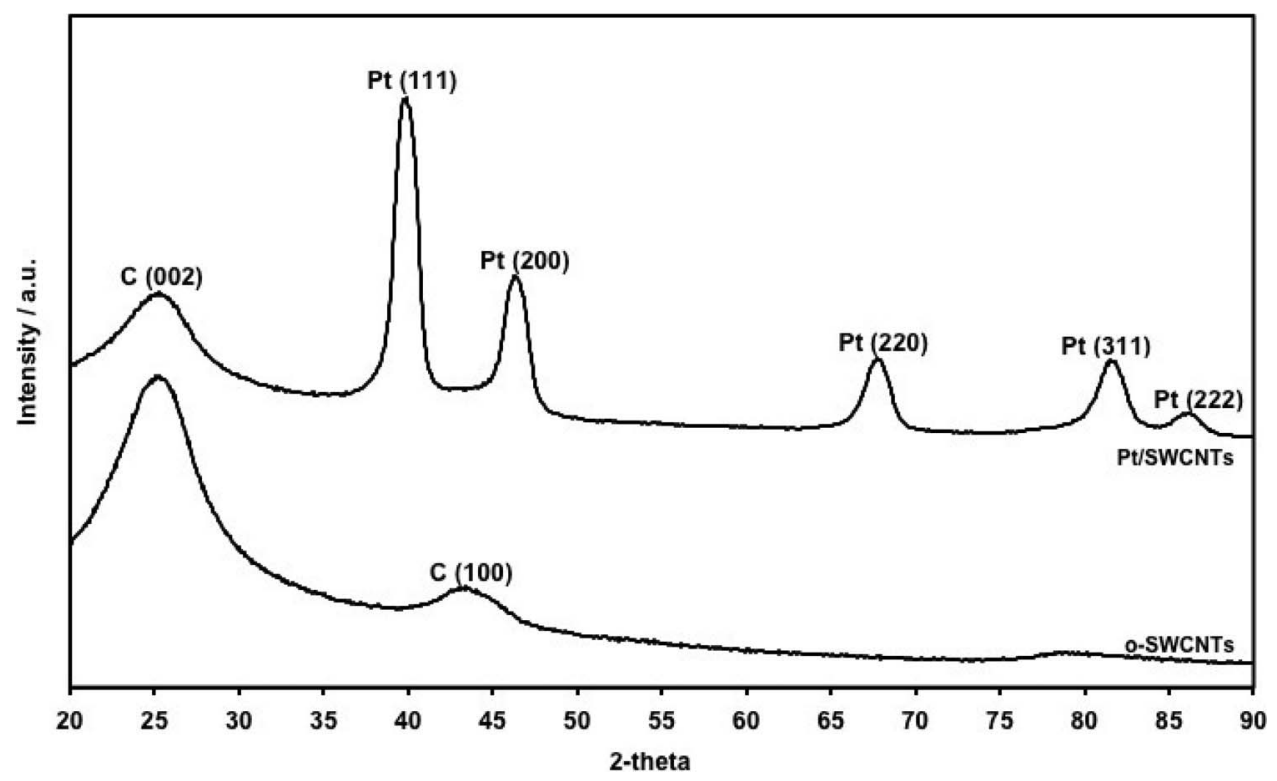

Figure 10. X-ray diffraction patterns for o-SWCNTs and Pt/SWCNTs samples. 
(a)

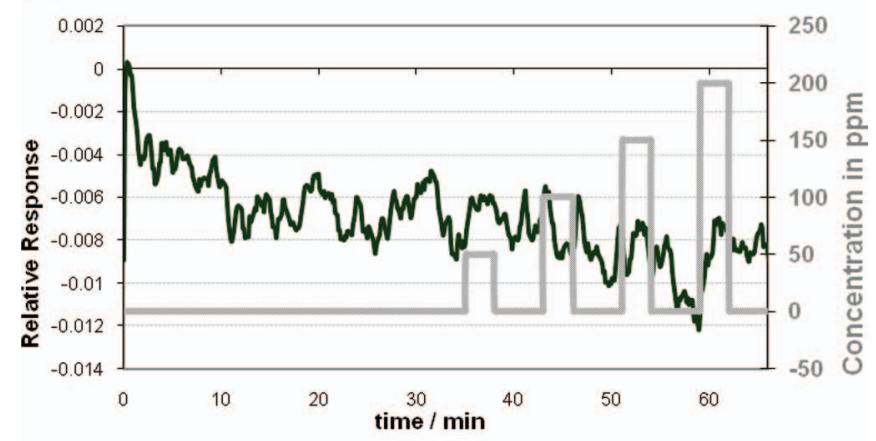

(b)
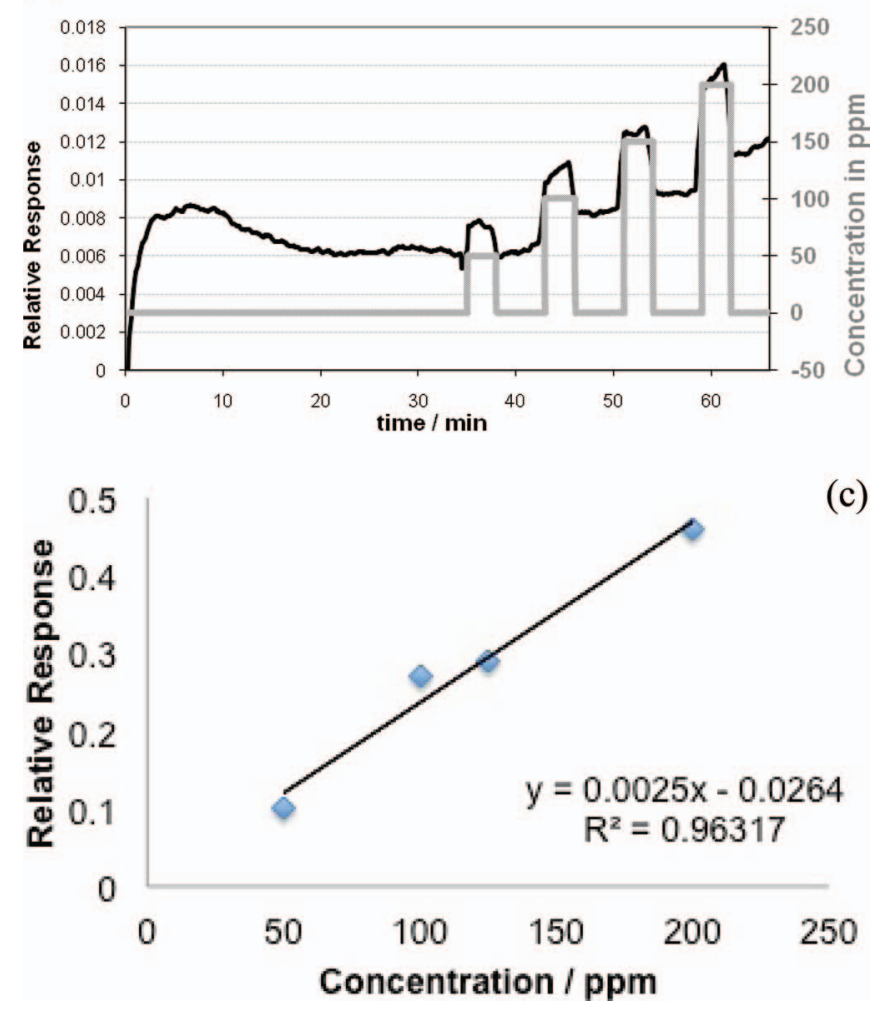

Figure 11. (a) o-SWNTs exposed to $\mathrm{CH}_{4}$ did not show any response to any of the tested concentrations. (b) Pt/SWNTs sensor response to 50, 100, 125 and $200 \mathrm{ppm}$ of $\mathrm{CH}_{4}$ at room temperature. (c) Calibration curve for sensor in $10 \mathrm{~b}$. Relative response to $\mathrm{CH}_{4}$ as function of concentration showing a linear fit.

electrode disk could help to optimize and control Pt nanoparticle size and density. Materials prepared with this technique could be used not only as sensing material as we demonstrated here but also for a wide variety of applications like catalysts for fuel cells and nanoelectronics, among others.

\section{Acknowledgments}

The authors acknowledge the members of both the NASA Center for Advanced Nanoscale Materials (CANM) grant \# NNX08BA48A and NNX10AQ17A, the Material Characterization Center (MCC) of the University of Puerto Rico for the XPS and EDS data and NASA-
ARC Nano-sensor group. Thanks are also given to A. Hernández and O. García, and T. Luna (University of Puerto Rico -Mayagüez) for the XRD and ICP data, respectively. In addition, the authors acknowledge the following agencies: The Welch Foundation Agency, project AX-1615: Controlling the Shape and Particles Using Wet Chemistry Methods and Its Application to Synthesis of Hollow Bimetallic Nanostructures, the National Science Foundation (NSF) PREM grant number: DMR-0934218: Oxide and Metal Nanoparticles: The Interface between life sciences and physical sciences, and CONACYT-Mexico grant number: 106437 . The authors would also like to thank the International Center for Nanotechnology and Advanced Materials (ICNAM) at UTSA, and the RCMI Center for Interdisciplinary Health Research (CIHR), and the project award number 2G12RR013646-11 from the National Center for Research Resources. E. Contes-de Jesus acknowledge financial support from PR-LSAMP, Puerto Rico Space grant, AGEP Fellowship Program, and NASA GSRP Fellowship under grant \# NNX09AM23H.

\section{References}

1. S. Iijima, Nature, 354, 56 (1991).

2. M. Trojanowicz, TrAC, Trends Anal. Chem., 25, 480 (2006).

3. M. Valcarcel, S. Cardenas, and B. M. Simonet, Anal. Chem., 79, 4788 (2007).

4. S. Ciraci, S. Dag, T. Yildirim, O. Gülseren, and R. T. Senger, J. Phys.: Condens. Matter, 16, R901 (2004)

5. R. P. Raffaelle, B. J. Landi, J. D. Harris, S. G. Bailey, and A. F. Hepp, Mater. Sci. Eng., B, 116, 233 (2005).

6. Y. L. Kim, B. Li, X. H. An, M. G. Hahm, L. Chen, M. Washington, P. M. Ajayan, S. K. Nayak, A. Busnaina, S. Kar, and Y. J. Jung, Acs Nano, 3, 2818 (2009).

7. D. Vairavapandian, P. Vichchulada, and M. D. Lay, Anal. Chim. Acta, 626, 119 (2008).

8. A. Goldoni, L. Petaccia, S. Lizzit, and R. Larciprete, J. Phys.: Condens. Matter, 22, 013001 (2010).

9. D. Rathod, C. Dickinson, D. Egan, and E. Dempsey, Sens. Actuators, B, 143, 547 (2010).

10. X. G. Li and I. M. Hsing, Electrochim. Acta, 51, 5250 (2006).

11. J. H. Wee, K. Y. Lee, and S. H. Kim, J. Power Sources, 165, 667 (2007).

12. M. H. Yang, Y. H. Yang, Y. L. Liu, G. L. Shen, and R. Q. Yu, Biosensors \& Bioelectronics, 21, 1125 (2006).

13. X. X. Chen, N. Li, K. Eckhard, L. Stoica, W. Xia, J. Assmann, M. Muhler, and W. Schuhmann, Electrochem. Commun., 9, 1348 (2007).

14. D. Santiago, G. G. Rodriguez-Calero, H. Rivera, D. A. Tryk, M. A. Scibioh, and C. R. Cabrera, J. Electrochem. Soc., 157, F189 (2010).

15. D. Santiago, M. Cruz-Quinonez, D. A. Tryk, and C. R. Cabrera, ECS Transactions, 3, 35 (2007).

16. J. Li, Y. J. Lu, Q. Ye, M. Cinke, J. Han, and M. Meyyappan, Nano Lett., 3, 929 (2003).

17. Y. J. Lu, J. Li, J. Han, H. T. Ng, C. Binder, C. Partridge, and M. Meyyappan, Chem. Phys. Lett., 391, 344 (2004).

18. B. I. Rosario-Castro, E. J. Contes, M. Lebron-Colon, M. A. Meador, G. Sanchez-Pomales, and C. R. Cabrera, Mater. Charact., 60, 1442 (2009).

19. M. D. Obradovic, G. D. Vukovic, S. I. Stevanovic, V. V. Panic, P. S. Uskokovic, A. Kowal, and S. L. Gojkovic, J. Electroanal. Chem., 634, 22 (2009).

20. X. L. Chen, W. S. Li, C. L. Tan, W. Li, and Y. Z. Wu, J. Power Sources, 184, 668 (2008).

21. J. N. Barisci, G. G. Wallace, and R. H. Baughman, J. Electrochem. Soc., 147, 4580 (2000).

22. T. Vidakovic, M. Christov, and K. Sundmacher, Electrochim. Acta, 52, 5606 (2007).

23. J. J. Niu and J. N. Wang, Electrochim. Acta, 53, 8058 (2008).

24. J. J. Zhao, A. Buldum, J. Han, and J. P. Lu, Nanotechnology, 13, 195 (2002)

25. Q. Zhao, M. B. Nardelli, W. Lu, and J. Bernholc, Nano Lett., 5, 847 (2005).

26. T. Zhang, S. Mubeen, N. V. Myung, and M. A. Deshusses, Nanotechnology, 19, 332001 (2008)

27. X.-J. Huang and Y.-K. Choi, Sens. Actuators, B, 122, 659 (2007).

28. Y. Wang and J. T. W. Yeow, Journal of Sensors, 2009, 493904 (2009).

29. W.-D. Zhang and W.-H. Zhang, Journal of Sensors, 2009, 160698 (2009).

30. H. Chang, J. D. Lee, S. M. Lee, and Y. H. Lee, Appl. Phys. Lett., 79, 3863 (2001).

31. Z. Li, J. Li, X. Wu, S. Shuang, C. Dong, and M. M. F. Choi, Sens. Actuators, B, 139, 453 (2009).

32. L. Valentini, I. Armentano, L. Lozzi, S. Santucci, and J. M. Kenny, Mater. Sci. Eng., $C, 24,527$ (2004).

33. M. Penza, R. Rossi, M. Alvisi, D. Suriano, and E. Serra, Thin Solid Films, 520, 959 (2011). 